\title{
Caso clínico radiológico
}

\author{
ANÍBAL ESPINOZA ${ }^{1}$, SUSANA RENEDO ${ }^{1}$, MARÍA TERESA LÓPEZ² \\ 1. Servicio de Radiología. \\ 2. Servicio de Cirugía Infantil. \\ Hospital Clínico San Borja-Arriarán.
}

\section{Historia clínica}

Niño de 7 años de edad, sin antecedentes mórbidos, que consultó en servicio de urgencia por cuadro caracterizado por fiebre de hasta 39 grados, dolor abdominal en hipogastrio y disuria, de 24 horas de evolución. Al examen físico se constató dolor abdominal infraumbilical y abdomen en tabla que no permite mayor palpación. Se diagnosticó abdomen agudo quirúrgico, probablemente apendicitis aguda.

Se solicita ultrasonografía (US) abdominal que mostró una masa de estructura compleja,
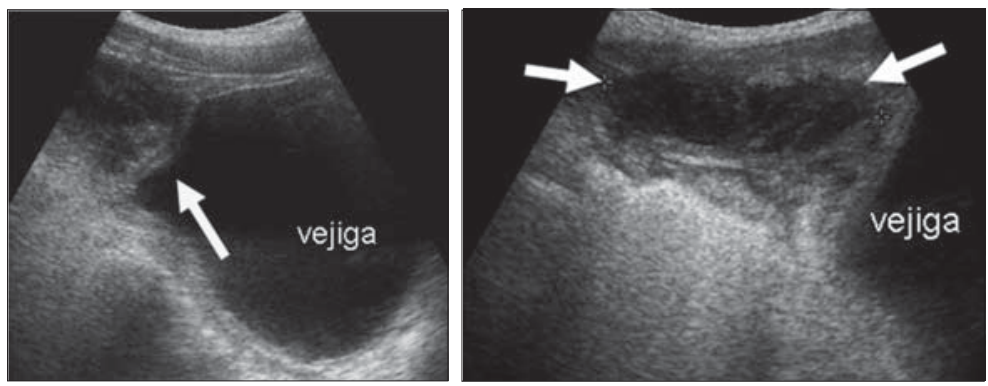

Figura 1a. US abdominal. Corte sagital (a) y transversal (b) en la región del hipogastrio. Se observa una masa compleja de paredes gruesas, con zonas de contenido líquido por sobre la vejiga (flechas). con áreas de contenido líquido, en la región infraumbilical a nivel de la línea media, en contacto con el techo vesical (figura 1). Aunque no estaba indicada, se solicitó además tomografía computarizada (TC) que confirma los hallazgos del la US (figura 2).

\section{¿Cuál es su hipótesis diagnóstica?}

Trabajo recibido el 16 de junio de 2008, devuelto para corregir el 22 de julio de 2008, segunda versión el 01 de agosto de 2008, aceptado para publicación el 06 de agosto de 2008.

Correspondencia a:

Aníbal Espinoza

E-mail: aespinoza@alemana.cl 


\section{Hallazgos radiológicos}

El hallazgo de una masa compleja de aspecto inflamatorio en la región hipogástrica, en un paciente con dolor abdominal y sensibilidad en esa zona al examen clínico, debe hacer plantear como primera posibilidad un quiste del uraco infectado. El diagnóstico diferencial debe incluir fundamentalmente una apendicitis aguda perforada y con formación de absceso, en un apéndice de situación medial o infraumbilical.

La cirugía confirmó el diagnóstico de un quiste del uraco infectado. El apéndice cecal era normal.

\section{Diagnóstico}

Quiste del uraco infectado.

\section{Discusión}

Las anomalías congénitas del uraco son poco frecuentes y se observan en aproximadamente uno de cada 330000 recién nacidos vivos.

Para entender estas anomalías es importante conocer la embriología normal del uraco. En la etapa embrionaria y en el día 16, el saco vitelino da origen a la alantoides, un delgado divertículo que se dirige hacia la placa coriónica. La alantoides será necesaria para el desarrollo de las vasos umbilicales y quedará ubicada próxima a la cloaca, que a su vez, dará origen a la vejiga y al intestino distal. El conducto epitelial que se extiende desde la porción alta de la cloaca, posteriormente la cúpula vesical, se conecta a través del anillo umbilical con estructuras extraembrionarias. La porción que se extiende desde la vejiga al ombligo se conoce como uraco y contribuye parcialmente a la formación de la vejiga. Durante la $5^{\mathrm{a}}$ semana de gestación se identifica un anillo umbilical primitivo. En este anillo se distinguen un tallo de conexión (cordón primitivo) que contiene la alantoides al centro, rodeada de dos arterias y una vena. Adyacente e inmediatamente cefálico, dentro del anillo primitivo, se encuentra el tallo del saco vitelino (conducto ónfalo-mesentérico).

Durante la $6^{\mathrm{a}}$ semana se oblitera el conduc- to alantoides y en la $7^{\mathrm{a}}$ semana la cloaca se divide en intestino distal y vejiga por el desarrollo del tabique urorectal. En el $5^{\circ}$ mes de gestación la vejiga desciende a la pelvis y el uraco se transforma en un cordón fibromuscular con epitelio central conocido también como ligamento umbilical medial.

La persistencia total o parcial de este conducto resultará en las diferentes formas de patología uracal.

El uraco persistente consiste en la persistencia de la comunicación entre la vejiga y el ombligo y corresponde al 50\% de las anomalías uracales. Como signo clínico principal presenta salida de orina por el ombligo en el recién nacido.

El quiste del uraco corresponde al 30\% de los casos y ocurre por obliteración de los extremos vesical y umbilical del conducto. La gran mayoría de ellos se complica con sobreinfección bacteriana, generalmente en la primera o segunda décadas de la vida. Esta se manifiesta clínicamente con dolor abdominal agudo, localizado en la región hipogástrica, como ocurrió en nuestro paciente.

El seno uracal corresponde al $15 \%$ de los casos y representa la persistencia de la porción cefálica o extremo vesical del uraco, comunicado al ombligo. Clínicamente se presenta con secreción umbilical o infección local.

El divertículo vesical es la anomalía menos frecuente y está presente en $5 \%$ de los casos. Corresponde a la persistencia de la porción vesical del conducto y en la mayoría de los casos es asintomático, aunque puede manifestarse con infección urinaria. Puede verse en asociación con el Síndrome de Prune-Belly.

El diagnóstico de todas estas anomalías puede ser confirmado con US, que es el examen de elección cuando clínicamente se sospecha esta patología. En la gran mayoría de los casos, no es necesario recurrir a técnicas más sofisticadas, como la TC o la Resonancia Magnética. En los casos de sospecha de divertículo del uraco, la uretrocistografía puede ser de utilidad para el diagnóstico.

El tratamiento consiste en la extirpación quirúrgica del remanente uracal, donde es importante la resección completa del uraco, por el riesgo eventual de aparición de carcinoma uracal 
en el largo plazo. Cuando existe infección, es aconsejable el tratamiento antibiótico previo a realizar la cirugía cuando ésta esté controlada. El tratamiento médico sin cirugía, presenta una alta probabilidad de reinfección.

En recién nacidos normales y sin patología uracal, es posible visualizar el remanente uracal en la US, donde aparece como una estructura tubular hipoecogénica que comunica la cúpula vesical con el ombligo. Normalmente, esta estructura involuciona dentro de los primeros seis meses de vida, después de lo cual sólo persiste una pequeña estructura fusiforme a nivel del techo vesical.

El granuloma umbilical es la causa más frecuente de ombligo húmedo. En recién nacidos con ombligo húmedo, la presencia de un remanente uracal normal en la US, puede ser malinterpretada como el factor causal. Cuando existe duda clínica, puede ser de utilidad el seguimiento con US, buscando su involución espontánea.

\section{Referencias}

1.- Ulloa I: Uraco persistente. Rev Chil Pediatr 1953; 24: 149-57.

2.- Brunch P, Kline-Fath B, Imhoff S, Calvo-Garcia M, Crombleholme T, Donnelly L: Allantoic cyst: a prenatal clue to patent urachus. Pediatr Radiol 2006; 36 : 1090-5.

3.- Zieger B, Sokol B, Rohrschneider W, Darge K, Tröger J: Sonomorphology and involution of the normal urachus in asymptomatic newbornes. Pediatr Radiol 1998; 28: 156-61.

4.- Zamora E, O'Brien A: Uraco: Anomalías del desarro1lo, características anatómicas y presentación de dos casos. Rev Chil Radiol 2006; 12: 9-11.

5.- Yu JS, Kim KW, Lee HJ, Lee YJ, Yoon CS, Kim MJ: Urachal remnant diseases: spectrum of CT and US findings. Radiographics 2001; 21:451-61. 